\title{
Caracterização química e efeito cicatrizante de quitosana, com baixos valores de massa molar e grau de acetilação, em lesões cutâneas
}

\section{Chemical characterization and healing effect of chitosan with low molar mass and acetylation degree in skin lesions}

\author{
Rodrigo Martins Fráguas' ${ }^{1}$, Denise Alvarenga Rocha1, Estela de Rezende Queiroz¹, \\ Celeste Maria Patto de Abreu ${ }^{1}$, Raimundo Vicente de Sousa² e Enio Nazaré de Oliveira Júnior ${ }^{3}$ \\ 'Departamento de Química, Universidade Federal de Lavras - UFLA, Lavras, MG, Brasil \\ ${ }^{2}$ Departamento de Medicina Veterinária, Universidade Federal de Lavras - UFLA, Lavras, MG, Brasil \\ ${ }^{3}$ Departamento de Química, Biotecnologia e Engenharia de Bioprocessos, \\ Universidade Federal de São João del-Rey - UFSJ, Campus Alto Paraopeba, Ouro Branco, MG, Brasil \\ *rodrigofraguas1@hotmail.com
}

\begin{abstract}
Resumo
Inúmeras pesquisas buscam fármacos com propriedades cicatrizantes, capazes de reparar lesões cutâneas. O objetivo deste estudo foi caracterizar quimicamente uma quitosana e avaliar seus efeitos cicatrizantes em lesões cutâneas de ratos. A quitosana foi caracterizada quanto à viscosidade, massa molar, grau de acetilação, análise elementar, termogravimetria e espectroscopia na região do infravermelho. As propriedades cicatrizantes da quitosana foram avaliadas, para isso ratos adultos foram submetidos à excisão tecidual e tratados por 21 dias, sendo avaliados parâmetros macroscópicos, semanalmente, e microscópicos, ao final do experimento. A quitosana apresentou viscosidade de $5 \mathrm{mPa}$, baixo grau de acetilação $(\mathrm{GA}=5,9 \%)$ e massa molar $(132,0 \mathrm{kDa})$. Por análise elementar observou-se que a composição da quitosana se aproxima da fórmula $\mathrm{C}_{6} \mathrm{H}_{11} \mathrm{O}_{4} \mathrm{~N}$, suas principais bandas características foram observadas no espectro de infravermelho e a curva termogravimétrica mostrou que esta apresenta somente duas etapas de decomposição. Não houve diferença significativa na histologia, no $21^{\circ}$ dia da lesão, entre os grupos controle e tratado, porém, macroscopicamente, a quitosana promoveu redução de $81,4 \%$ da largura das lesões, porcentagem significativamente superior à observada no grupo controle $(71,2 \%)$, auxiliando a cura de lesões cutâneas, o que reforça seu potencial de aplicação médica.
\end{abstract}

Palavras-chaves: grau de acetilação, análise termogravimétrica, propriedades cicatrizantes, quitosana.

\begin{abstract}
Several researches look for drugs with healing properties, capable to cure skin lesions. The objective of this study was to chemically characterize one chitosan and evaluate its healing effects in mice skin lesions. The chitosan was characterized in relation to the viscosity, molar mass, acetylation degree, elementary analysis, thermogravimetry and infrared spectroscopy. To evaluate the healing properties of chitosan mices were submitted to tissue excision and treated during 21 days. The macroscopic parameters were weekly evaluated and the microscopic parameters at the end of the experiment. Chitosan presented viscosity of $5 \mathrm{mPa} \mathrm{s}$, low acetylation degree $(\mathrm{GA}=5.9 \%)$ and molar mass of $132.0 \mathrm{kDa}$. By elemental analysis, we observed that the composition of chitosan is similar to the formula $\mathrm{C}_{6} \mathrm{H}_{11} \mathrm{O}_{4} \mathrm{~N}$, its main characteristic bands were observed in the infrared spectrum and the thermogravimetric curve showed two decomposition steps. There was no significant difference on the histology between the control and the treated group after the $21^{\text {st }}$ day of lesion. Macroscopically, chitosan caused the reduction of $81.4 \%$ of the lesions width, which is significantly superior to the observed reduction in the control group (71.2\%), thus helping the cure of skin lesions. These results reinforces its potential use for medical application.
\end{abstract}

Keywords: degree of acetylation, thermogravimetric analysis, healing properties, chitosan.

\section{Introdução}

A pele reveste quase a totalidade da superfície corpórea e quando um dano tecidual compromete a continuidade desse tecido, desencadeia-se o fenômeno biológico da cicatrização.

A reparação tecidual é um processo que envolve três fases distintas: inflamação, formação e deposição do tecido de granulação e remodelamento da matriz extracelular ${ }^{[1,2]}$. 
O reparo cutâneo torna-se indispensável à vida e quanto mais rápido este processo ocorrer, menor será o tempo de exposição do organismo a uma série de patógenos ${ }^{[3]}$. Fatores sistêmicos e locais podem interferir no processo de cicatrização da pele e retardar sua recuperação, representando um desafio clínico a ser superado ${ }^{[4]}$. Adicionalmente, muitos eventos bioquímicos e celulares estão envolvidos no processo de cicatrização e na qualidade da cicatriz formada e resultam da resposta tecidual à lesão ${ }^{[5]}$. Desta forma, a reparação tecidual é um fenômeno de grande interesse para profissionais da área de saúde, uma vez que sua eficiência acelera o processo de reabilitação do paciente ${ }^{[6]}$.

Diversas pesquisas buscam novos agentes cicatrizantes para o tratamento de lesões cutâneas ${ }^{[7-9]}$, pois embora existam, no mercado, inúmeras opções de curativos e tratamentos para estas lesões, grande parte dos produtos apresenta custo elevado ao paciente. Neste contexto, a quitosana surge como uma alternativa para o tratamento de lesões cutâneas, uma vez que esta é uma aminoglucopirananas, compostas dos monômeros N-acetil-D-glicosamina (GlcNac) e D-glicosamina $(\mathrm{GlcN})$, obtida a partir de resíduos de crustáceos provenientes da indústria pesqueira ${ }^{[10]}$.

Pesquisas revelam que a quitosana pode atuar como excelente cicatrizante em feridas, além de possuir boa capacidade de adesão tecidual ${ }^{[11]}$. Outros trabalhos descrevem o efeito estimulante da quitosana no processo de cicatrização, na formação de tecido de granulação, na angiogênese, na formação de fibras de colágeno e na ativação da resposta imune $e^{[12-15]}$.

Assim, a versatilidade e biocompatibilidade da quitosana despertam interesse de inúmeros pesquisadores que visam o desenvolvimento de novos produtos, baseados em suas aplicações tecnológicas e biomédicas, a fim de obter curativos que atuem diretamente no processo de cicatrização de feridas. Diante do exposto, o presente estudo tem como objetivo caracterizar quimicamente uma amostra de quitosana com baixos valores de massa molar e grau de acetilação e estudar seu efeito no processo de cicatrização em lesões cutâneas de ratos.

\section{Experimental}

A amostra de quitosana (nome comercial Chitoclear ${ }^{\circledR}$ ), com granulometria de 100 mesh $(0,149 \mathrm{~mm})$, foi gentilmente cedida pela Primexehf da Islândia, com número de lote: 3493 . O polímero foi caracterizado utilizando os procedimentos descritos a seguir.

\subsection{Determinação da massa molar média absoluta por cromatografia de permeação em gel}

A quitosana foi dissolvida em tampão acetato de sódio, $\mathrm{pH} 4$, na proporção $1: 100(\mathrm{~m} / \mathrm{v})$, filtrada em filtro $0,45 \mu \mathrm{m}$ e, em seguida, submetida à cromatografia de permeação em gel. A análise foi realizada utilizando duas colunas em série Ultrahydrogel ${ }^{\mathrm{TM}}$ Linear 7,8 $\times 300 \mathrm{~mm}$, injetor Viscotek GPC max VE 2001 Solvent/SAMPLE MODULE e detector Viscotek TDA302 Triple Detector Array, usando como fase móvel tampão acetato de sódio $\mathrm{pH} 4$. Injetou-se $100 \mu \mathrm{L}$ da amostra, a uma vazão de $0,8 \mathrm{~mL} \mathrm{~min}^{-1}$ e foram usados como detectores: índice de refração (IR), viscosidade (DP) e espalhamento de luz (RALS).

\subsection{Determinação do grau de acetilação}

O grau de acetilação (GA) da quitosana foi determinado pelo método de titulação potenciométrica, segundo Raymond et al. ${ }^{[16]}$. A amostra foi dissolvida em $\mathrm{HCl} 0,1 \mathrm{~mol} \mathrm{~L}^{-1}$, na proporção 1:100 (m/v), e titulada com solução de $\mathrm{NaOH} 0,1 \mathrm{~mol} \mathrm{~L}^{-1}$ sob agitação contínua. Os valores de GA foram calculados através da Equação 1:

$$
G A=\frac{\left(V_{\mathrm{NaOH}} \times M_{q u}\right) \times 100}{\left(1000 \times M_{\mathrm{NaOH}} \times m_{q u}\right)}
$$

onde, $\mathrm{GA}=$ grau de acetilação de quitosana $(\%) ; \mathrm{m}_{\mathrm{qu}}=$ massa da amostra de quitosana $(\mathrm{g}) ; \mathrm{M}_{\text {qu }}=$ massa molar da unidade de glicosamina $\left(161 \mathrm{~g} \mathrm{~mol}^{-1}\right) ; \stackrel{q u}{V}_{\mathrm{NaOH}}=$ volume da solução de $\mathrm{NaOH}\left(0,1 \mathrm{~mol} \mathrm{~L}^{-1}\right)$ usado para neutralizar os grupos amino livres protonados $(\mathrm{mL})$ e $\mathrm{M}_{\mathrm{NaOH}}=$ concentração molar real da solução de $\mathrm{NaOH}\left(\mathrm{mol} \mathrm{L}^{-1}\right)$.

\subsection{Análise elementar}

Uma amostra de $2 \mathrm{mg}$ de quitosana foi seca em estufa a $103 \pm 2{ }^{\circ} \mathrm{C}$ e, posteriormente, acondicionada em analisador elementar Vario Micro Cube, sendo obtidos os teores em nitrogênio, carbono, hidrogênio, enxofre e, por diferença, o teor em oxigênio. As temperaturas do tubo de combustão e redução foram de $1200^{\circ} \mathrm{Ce} 850^{\circ} \mathrm{C}$, respectivamente, usando hélio como gás de arraste e oxigênio como gás oxidante.

\subsection{Espectroscopia na região do infravermelho}

Aproximadamente $1,5 \mathrm{mg}$ da quitosana foi seca em estufa a vácuo, por 15 horas, a $60^{\circ} \mathrm{C}$. Após este período, adicionou-se $100 \mathrm{mg}$ de $\mathrm{KBr}$ e a mistura foi homogeneizada em almofariz de ágata. A pastilha preparada foi deixada em estufa a vácuo, a $110^{\circ} \mathrm{C}$, por 20 horas, e o espectro de infravermelho registrado em espectrofotômetro Bomem-Michelson FT-IR, MB 102.

\subsection{Análise termogravimétrica}

A curva foi obtida em módulo termogravimétrico TGA 2050, acoplado a um analisador térmico TA 2000 da TA instruments. A atmosfera empregada foi de $\mathrm{N}_{2}$ st, com

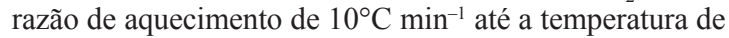
$400^{\circ} \mathrm{C}$ e o fluxo de gás de $30 \mathrm{~mL} \mathrm{~min}^{-1}$.

\subsection{Ensaio biológico}

Este ensaio biológico foi aprovado pela comissão de Ética no uso de animais (CEUA) da Universidade Federal de Lavras-UFLA, através do protocolo $\mathrm{N}^{\circ} 007 / 2012$. Foram utilizados 10 ratos adultos jovens, (Rattus novergicus), fêmeas, com peso médio inicial de $186 \pm 5 \mathrm{~g}$ da linhagem Wistar, provenientes do Biotério do Departamento de Medicina Veterinária da Universidade Federal de Lavras. Os animais foram divididos, aleatoriamente, em 2 grupos: controle (C) e quitosana (Q), mantidos em gaiolas individuais, em sala com temperatura de $25 \pm 3^{\circ} \mathrm{C}$, ciclo claro/escuro de 12 horas e com acesso à ração para roedores e água $\mathrm{ad}$ libitum, por uma semana para adaptação e, em seguida, iniciou-se o experimento. 


\subsection{Indução das lesões cutâneas}

Os animais foram pesados e anestesiados com tiopental $35 \mathrm{mg} \mathrm{Kg}^{-1}$, por via intraperitoneal, e lidocaína, um anestésico local, foi infiltrado na região onde foi feito a incisão. Os animais foram mantidos em, mesa operatória, em posição de pronação, realizou-se a tricotomia na região mediana do dorso, em seguida foi realizada uma assepsia com álcool iodado a 2\%. Para demarcação da área, utilizou-se uma régua com a área circular contendo $1 \mathrm{~cm}$ de diâmetro e realizou-se abertura cutânea na região dorsal dos animais, com o auxílio de uma tesoura cirúrgica.

\subsection{Tratamento}

A partir do pós-operatório, os ratos do grupo quitosana foram tratados, diariamente, com $10 \mathrm{mg}$ da quitosana, pulverizada diretamente sobre cada lesão, sem auxílio de diluentes, durante 21 dias, sendo constituídas as semanas 0 (dia da indução da lesão) e semanas 1, 2 e 3 (7, 14 e 21 dias após a indução da lesão, respectivamente). Os animais do grupo controle não receberam qualquer tratamento sobre a lesão.

\subsection{Análise histológica}

Após a eutanásia dos animais, utilizando tiopental, as lesões cutâneas foram seccionadas, desidratadas e diafanizadas em temperatura ambiente. Em seguida, estas foram incluídas em parafina, submetidas a cortes de microtomia e coradas com hematoxilina-eosina.

\section{Resultados e Discussões}

\subsection{Viscosidade, massa molar, grau de acetilação e análise elementar}

A viscosidade, o grau de acetilação e a massa molar da quitosana foram incialmente investigadas, uma vez que as propriedades químicas, físicas e biológicas da quitosana não dependem apenas do seu GA, mas, também da distribuição média dos grupos acetil ao longo da cadeia principal, além da sua massa molar. Assim, os resultados da viscosidade, massa molar absoluta, grau de acetilação e análise elementar da quitosana são apresentados na Tabela 1 .

A viscosidade da quitosana foi de $5 \mathrm{mPa} \times \mathrm{s}$, valor que reflete sua resistência ao escoamento e é influenciado por diversos fatores, como o peso molecular, concentração, força iônica, $\mathrm{pH}$, temperatura e grau de acetilação ${ }^{[17]}$.

A quitosana apresentou massa molar absoluta de $132,0 \mathrm{kDa}$, valor inferior aos observados por Lin e Chao ${ }^{[18]}$, que obtiveram, em diferentes quitosanas, massa molar variando entre 150 a $1250 \mathrm{kDa}$. A massa molar absoluta está diretamente relacionada à solubilidade da quitosana, pois quanto maior a cadeia, maior é sua massa molar, o que favorece as interações entre os segmentos e, consequentemente, diminui a solubilidade da quitosana.

O GA da quitosana, obtido por titulação potenciométrica, foi de $5,9 \%$, inferior aos reportados por Santos et al. ${ }^{[19]}$, que obtiveram, em diferentes quitosanas comerciais, graus de acetilação variando entre 9,8 e $23,0 \%$. Este grau também está relacionado com a solubilidade da quitosana, em meios de acidez moderada, pois seu valor expressa a quantidade de grupos amino disponíveis para protonação e que geram cargas $\left(-\mathrm{NH}_{3}^{+}\right)$na cadeia polimérica. Quanto menor o valor do GA, maior a quantidade de cargas presentes na cadeia e mais importante é a repulsão eletrostática entre elas, consequentemente, maior será a solubilidade da quitosana ${ }^{[20,21]}$.

Desta forma, a massa molar e o GA obtidos para a quitosana, neste estudo, são inferiores aos observados pelos autores supracitados, o sugere que esta apresenta melhor solubilidade, em soluções de acidez moderada.

A composição percentual de nitrogênio, carbono e hidrogênio da quitosana (Tabela 1) diferiu ligeiramente da encontrada por Santos et al. ${ }^{[19]}$, que obtiveram, em diferentes quitosanas comerciais, porcentagens variando entre 7,0 e $8,5 \% ; 41,2$ e $44,5 \%$ e 6,0 e $6,7 \%$, para nitrogênio, carbono e hidrogênio, respectivamente.

Entretanto, a composição da quitosana se aproxima da fórmula $\mathrm{C}_{6} \mathrm{H}_{11} \mathrm{O}_{4} \mathrm{~N}$, para a unidade de repetição, quando se desconta o teor de água presente na amostra. A hidratação da quitosana pode ser explicada uma vez que a mesma apresenta forte afinidade pela água e, no estado sólido, as macromoléculas podem apresentar estruturas distorcidas, que são facilmente hidratadas ${ }^{[22]}$. Adicionalmente, deve-se considerar que a análise elementar é um método conveniente para análise de quitosana, somente na ausência de proteína residual ${ }^{[19,23]}$.

\subsection{Infravermelho}

O espectro de absorção da quitosana, no infravermelho, é apresentado na Figura 1.

As principais bandas observadas no espectro da quitosana foram: banda de estiramento axial de $\mathrm{OH}$ entre 3440 a $3480 \mathrm{~cm}^{-1}$, que apareceu sobreposta à banda de estiramento $\mathrm{N}-\mathrm{H}$; deformação axial de $\mathrm{C}=\mathrm{O}$ de amida (entre 1661 e $1671 \mathrm{~cm}^{-1}$ ); deformação angular de N-H (entre 1583 a $1594 \mathrm{~cm}^{-1}$ ); deformação angular simétrica de $\mathrm{CH}_{3}$ (entre 1380 a $1383 \mathrm{~cm}^{-1}$ ); deformação axial de $-\mathrm{CN}$ de amida (próximo a $1425 \mathrm{~cm}^{-1}$ ) e deformação axial de $-\mathrm{CN}$ de grupos amino (entre 1308 a $1380 \mathrm{~cm}^{-1}$ ), além de bandas de estruturas de polissacarídeos na região de $890-1156 \mathrm{~cm}^{-1}$.

Todas as bandas características, observadas no presente estudo, são semelhantes àquelas descritas por Brugnerotto et al. ${ }^{[23]}$ e por Santos et al. ${ }^{[19]}$ e estão presentes na amostra investigada.

Tabela 1. Viscosidade, grau de acetilação (GA), massa molar absoluta (Mw) e análise elementar da quitosana.

\begin{tabular}{|c|c|c|c|c|c|c|}
\hline & \multirow{2}{*}{$\begin{array}{c}\text { Viscosidade } \\
(\mathrm{mPa} \times \mathrm{s})^{1}\end{array}$} & \multirow[t]{2}{*}{ Mw (kDa) } & \multirow[t]{2}{*}{ GA (\%) } & \multicolumn{3}{|c|}{ Composição (\%) } \\
\hline & & & & $\mathrm{N}^{2}$ & $\mathrm{C}^{3}$ & $\mathbf{H}^{4}$ \\
\hline Quitosana & 5,0 & $132,0 \pm 1,0$ & $5,9 \pm 0,1$ & $8,1 \pm 0,8$ & $38,4 \pm 3,7$ & $6,9 \pm 0,5$ \\
\hline
\end{tabular}

${ }^{1}$ Informação cedida pelo fabricante (Primexehf). A viscosidade foi determinada usando-se um reõmetro de Brookfield Programmable DV-II, sob as seguintes condições: $1 \%(\mathrm{~m} / \mathrm{m})$ de quitosana em solução de ácido acético $1 \%(\mathrm{v} / \mathrm{v})$, taxa de deformação $20 \mathrm{rpm}$ e temperatura de $25^{\circ} \mathrm{C}$.

${ }^{2}$ Nitrogênio. ${ }^{3}$ Carbono. ${ }^{4}$ Hidrogênio. 


\subsection{Análise termogravimétrica}

A curva de termogravimetria da quitosana apresentou somente duas etapas de decomposição (Figura 2). O primeiro estágio, próximo a $100^{\circ} \mathrm{C}$, refere-se ao desprendimento de água adsorvida ao biopolímero, enquanto que no segundo estágio, entre as temperaturas de 200 e $400^{\circ} \mathrm{C}$, a decomposição acontece sobretudo por desacetilação e despolimerização do composto. Observa-se, no segundo estágio, que o patamar final encontra-se indefinido, porém, como a atmosfera é a de um gás inerte, esta perda de massa está relacionada principalmente com o efeito térmico, do que com o efeito reaciona ${ }^{[24]}$. Em temperaturas superiores a $400^{\circ} \mathrm{C}$, deverão ocorrer degradações correspondentes aos resíduos finais do polímero ${ }^{[25]}$.

É importante frisar também que o material analisado, em atmosfera inerte $\left(\mathrm{N}_{2}\right)$, apresenta boa estabilidade térmica até temperaturas próximas de $300^{\circ} \mathrm{C}^{[25]}$.

\subsection{Ensaio biológico}

A quitosana, quando pulverizada sobre as lesões cutâneas dos animais, foi dissolvida no local de aplicação, não sendo observada a formação de particulados na superfície da ferida.

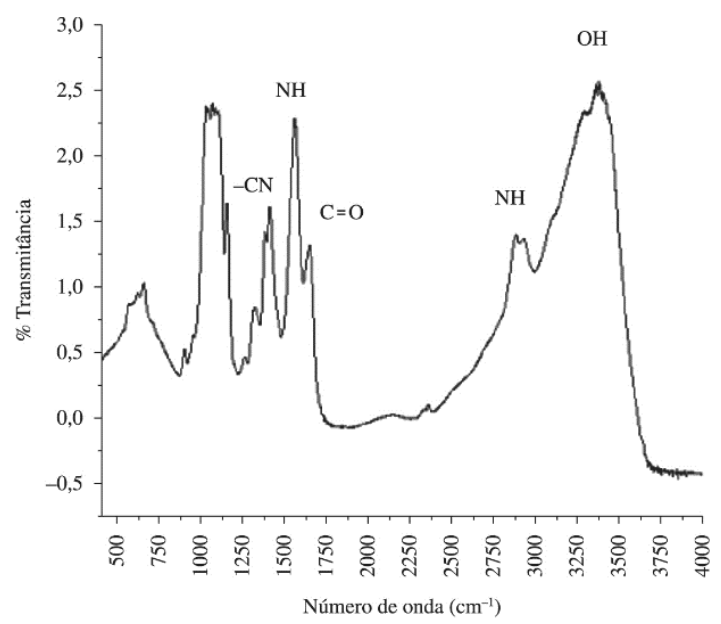

Figura 1. Espectro de absorção na região do infravermelho da quitosana.

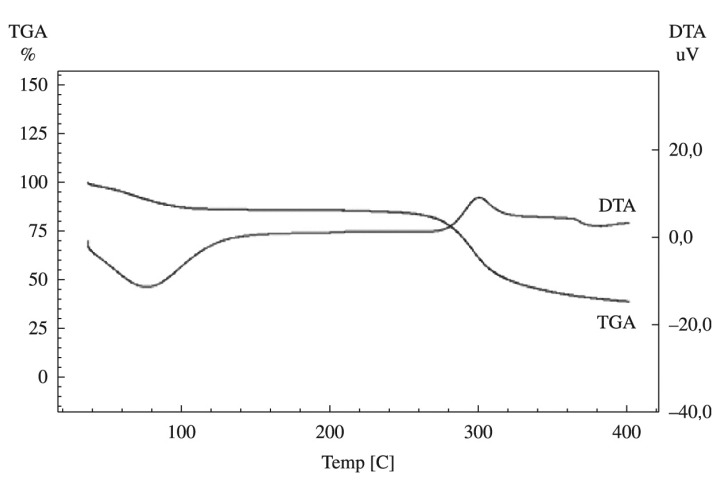

Figura 2. Curva termogravimétrica para a amostra de quitosana, sob atmosfera de $\mathrm{N}_{2}$ st (vazão de gás $30 \mathrm{~mL} \mathrm{~min}^{-1}$ e razão de aquecimento de $\left.10^{\circ} \mathrm{C} \mathrm{min}^{-1}\right)$.
As evoluções na cicatrização da ferida, durante o experimento, são apresentadas na Figura $3 \mathrm{a}$ e $b$.

Observa-se que no decorrer das semanas, houve uma redução no tamanho da lesão, entretanto esta redução foi mais evidente na largura que no comprimento da ferida (Figura 3a), comportamento verificado em ambos os grupos analisados. A diminuição da área da lesão ocorre devido aos mecanismos de contração e epitelização, durante o processo de cicatrização ${ }^{[26]}$.

Na evolução da cicatrização da lesão cutânea, tanto no grupo controle como no grupo tratado com quitosana, houve formação de crostas superficiais até a semana 1 ( $7^{\circ}$ dia), a partir da qual houve um espessamento desta crosta. Porém, após a semana 2 ( $14^{\circ}$ dia), a crosta se destacou da lesão, permitindo que o medicamento atuasse diretamente na ferida e evoluindo para tecido de granulação e epitelização até a semana 3 ( $21^{\circ}$ dia) (Figura $\left.3 b\right)$. A presença de crosta em feridas também foi observada por Oliveira et al. ${ }^{[27]}$ que relataram que sua presença favorece o processo de cicatrização.

Nesse estudo, foram avaliados a largura e o comprimento da lesão, alternativamente à sua área, em decorrência das pequenas variações nos formatos das lesões, ocorridas durante o procedimento cirúrgico. Assim, as porcentagens de comprimento e largura das lesões, ao longo das semanas, nos animais do grupo controle e tratados com a quitosana, são mostradas na Figura $4 \mathrm{a}$ e b.

$\mathrm{Na}$ Figura 4a, é possível notar redução no comprimento da lesão dos animais de ambos os grupos, ao longo das semanas. Na semana 0, a lesão foi medida no dia do procedimento cirúrgico, sendo observadas $100 \%$ do comprimento, em todos os grupos estudados. Na semana 1 observou-se uma

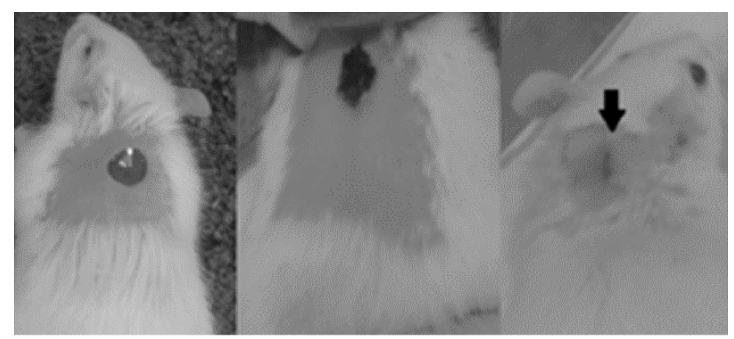

(a)

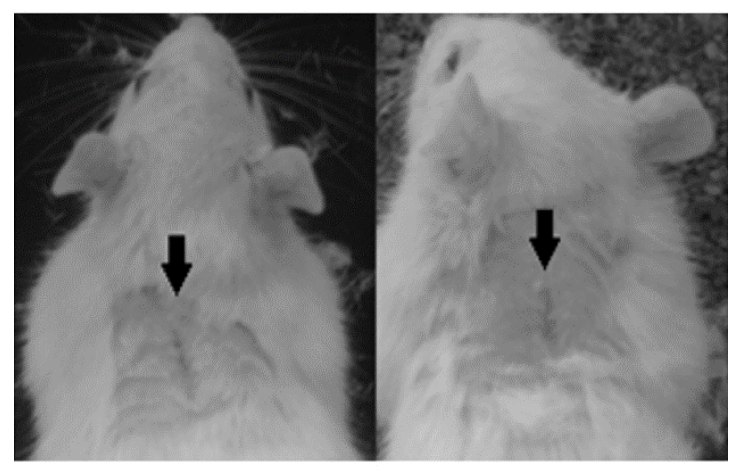

(b)

Figura 3. Lesão cutânea em animais. Em (a) no grupo controle, na semana 0,1 e 2 do pós operatório, respectivamente, e em (b) em animais do grupo controle (esquerda) e tratados com quitosana (direita) na semana 3 do pós operatório. 
pequena redução no comprimento das lesões, enquanto que nas semanas 2 e 3 esta redução foi mais evidente, porém, em nenhuma das semanas a redução do comprimento foi significativa. Isto provavelmente se deve à presença de crosta, que pode ter dificultado a absorção da quitosana e ao fato de que a retração tecidual ocorreu no sentido horizontal e promoveu uma pequena redução no comprimento, formando uma cicatriz que aparece como uma linha vertical, o que pode ser visualizado na Figura $3 \mathrm{a}$ e $\mathrm{b}$.

$\mathrm{Na}$ Figura $4 b$, verifica-se que na semana 0 , foram observados $100 \%$ da largura das lesões e, no decorrer das semanas, houve uma grande redução da largura destas lesões em ambos os grupos, entretanto, a redução da largura, ao final do experimento (semana 3 ), foi significativamente superior no grupo quitosana. No ensaio da cicatrização, os resultados revelaram que a quitosana possui uma atividade significativa na promoção da cura de lesões cutâneas, já que promoveu uma redução de $81,4 \%$ das lesões, redução significativamente superior à observada no grupo controle $(71,2 \%)$, resultado que pode ser evidenciado quando se compara a primeira $\mathrm{e}$ última semana do experimento.

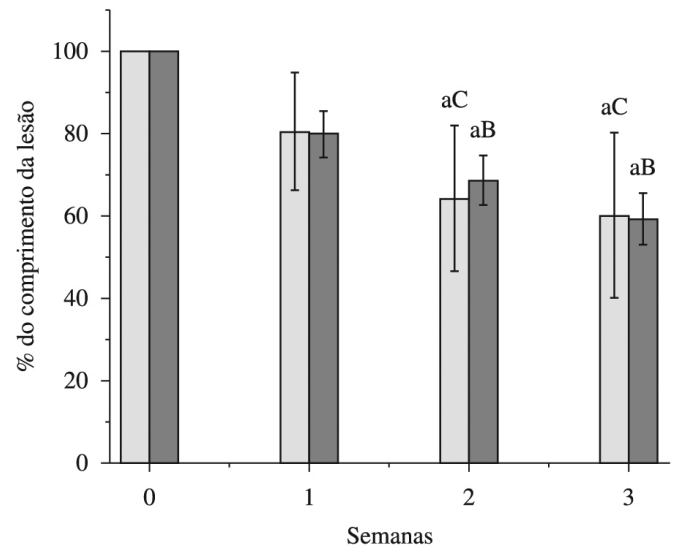

(a)

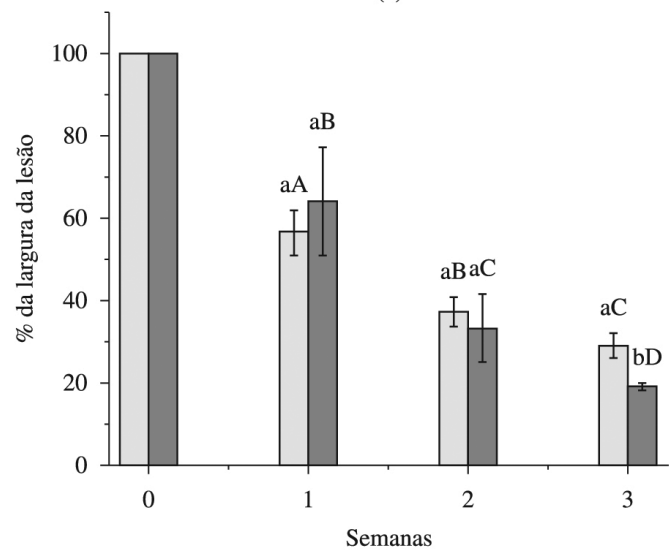

(b)

$\square$ Controle $\square$ Quitosana

Figura 4. Porcentagem do comprimento (a) e da largura (b) da lesão cutânea em ratos dos grupos controle e tratados com quitosana, durante as semanas. Médias seguidas pela mesma letra minúscula entre os tratamentos e maiúscula entre as semanas, não diferem entre si pelo teste Scott-Knott 5\%.
Como a cicatrização é um processo biológico natural através do qual os tecidos danificados tentam restabelecer sua integridade, o efeito da quitosana provavelmente se deve à aceleração da infiltração das células polimorfonucleares na área lesada, ao aumento da retirada dos feixes de fibrina, ao aumento da migração de fibroblastos para a área lesada, ao estímulo da migração de macrófagos, ao estímulo da proliferação de fibroblastos, à ativação de células inflamatórias e à produção de colágeno ${ }^{[13]}$.

Okamoto et al. ${ }^{[28]}$ afirmam que a quitosana também possui efeito analgésico tópico, decorrente da captura de hidrogênios ácidos liberados no local da inflamação pela ionização do grupo amínico $\left(\mathrm{NH}_{2}\right)$ para a forma de amônia $\left(\mathrm{NH}_{3}^{+}\right)$e, segundo Lee et al. ${ }^{[29]}$, a quitosana na forma de membranas ou gel, é um excelente veículo para fármacos no tratamento de lesões cutâneas, acelerando o processo de cicatrização.

Adicionalmente, a quitosana apresenta propriedades favoráveis de biocompatibilidade e bioatividade, além de ser atóxica, bactericida, fungicida e biodegradável e agir como composto cicatrizante, apresentando vantagem em relação aos polímeros sintéticos que, na sua grande maioria, são tóxicos ${ }^{[30-32]}$.

\subsection{Análise histológica}

A análise histológica realizada na semana $3\left(21^{\circ}\right.$ dia após a lesão) mostrou que nesta fase ocorreu a epitelização das lesões, observando-se a presença discreta de fibroblastos em $20 \%$ das lâminas, nos grupos controle e tratado com quitosana, não ocorrendo diferença na microscopia ótica no final do experimento (Figura 5). Ao longo das semanas, as lesões não foram avaliadas microscopicamente devido à quantidade de animais disponíveis. Desta forma, é importante que se amplie o estudo experimental, utilizando maior número de animais.

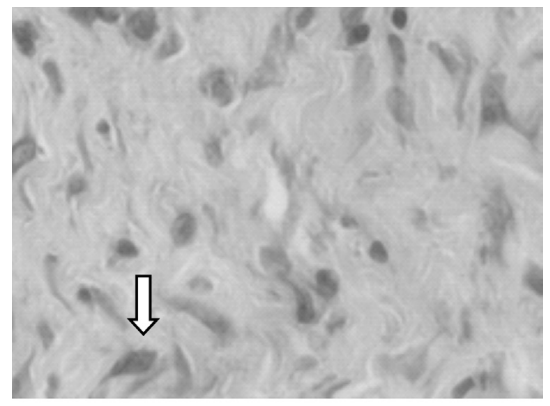

(a)

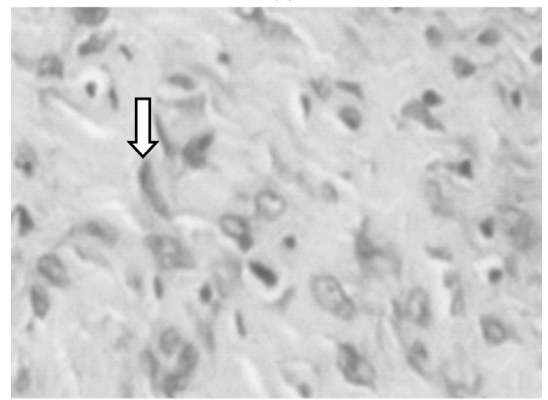

(b)

Figura 5. Aspecto histológico das lesões cutâneas ao $21^{\circ}$ dia de evolução pós-operatória de ratos do grupo controle (a) e do grupo tratado com quitosana (b). Lesão corada com Hematoxilina-Eosina. Aumento de 40 X. Fibroblasto indicado pela seta. 


\section{Conclusões}

As características químicas indicam que a quitosana analisada possui solubilidade elevada em soluções moderadamente ácidas, o que é relevante para suas aplicações em diversas áreas.

A análise do processo de cicatrização sob o ponto de visto macroscópico revela que a quitosana desempenha um importante papel na recuperação de lesões cutâneas agudas de ratos, acelerando o processo de cicatrização e proporcionando redução da largura da lesão, o que reforça seu potencial para aplicação médica.

\section{Agradecimentos}

Os autores agradecem ao CNPq, Capes e FAPEMIG.

\section{Referências}

1. Francis-Goforth, K. N., Harken, A. H., \& Saba, J. D. (2010). Normalization of diabetic wound healing. Surgery, 147(3), 446-449. http://dx.doi.org/10.1016/j.surg.2009.04.038. PMid:19703697

2. Obara, K., Ishihara, M., Ishizuka, T., Fujita, M., Ozeki, Y., Maehara, T., Saito, Y., Yura, H., Matsui, T., Hattori, H., Kikuchi, M., \& Kurita, A. (2003). Photocrosslinkable chitosan hydrogel containing fibroblast growth factor-2 stimulates wound healing in healing-impaired db/db mice. Biomaterials, 24(20), 34373444. http://dx.doi.org/10.1016/S0142-9612(03)00220-5. PMid:12809772

3. Sperandio, F. F. (2009). Avaliação da resposta tecidual em excisões realizadas no dorso de ratos submetida à terapia fotodinâmica com a utilização de corante azul de metileno (Dissertação de Mestrado). Universidade de São Paulo, São Paulo.

4. Paul, W., \& Sharma, C. P. (2004). Chitosan and alginate wound dressings: a short review. Trends in Biomaterials and Artificial Organs, 18(1), 18-23. Recuperado de http://medind.nic.in/taa/ t04/i1/taat04i1p18.pdf

5. Mendonça, A. C., Ferreira, A. S., Barbieri, C. H., Thomazine, J. A., \& Mazer, A. (2006). Effects of low-power pulsed ultrasound on second-intention healing of total skin injuries in rats. Acta Ortopédica Brasileira, 14(3), 152-157. http:// dx.doi.org/10.1590/S1413-78522006000300007.

6. Say, K. G., Gonçalves, R., Rennó, A. \& Parizotto, N. (2003). Tratamento fisioterápico de úlceras venosas crônicas através da laserterapia com dois tipos de comprimentos de onda. Revista Fisioterapia Brasil, 4(1), 39-48.

7. Nitz, A. C., Bins-Ely, J., D’Acampora, A. J., Tames, D. R., \& Corrêa, M. B. P. (2006). Estudo morfométrico no processo de cicatrização de feridas cutâneas em ratos, usando: Coronopu didymus e Calendula Officinali. Arquivos Catarinenses de Medicina, 35(4), 74-79. Recuperado de http://www.acm.org. br/revista/pdf/artigos/400.pdf

8. Hatanaka, E., \& Curi, R. (2007). Ácidos graxos e cicatrização: uma revisão. Revista Brasileira de Farmácia, 88(2), 53-58. Recuperado de http://www.rbfarma.org.br/files/PAG53a58_ ACIDOSGRAXOS.pdf

9. Barbosa, M. H., Zuffi, F. B., Maruxo, H. B., \& Jorge, L. L. R. (2009). Therapeutic properties of propolis for treatment of skin lesions. Acta Paulista de Enfermagem, 22(3), 318-322. http://dx.doi.org/10.1590/S0103-21002009000300013.

10. Peter, M. G. (2012). Chitin and chitosan from animal sources. In A. Steinbüchel (Ed.), Biopolymers: Polysaccharides II:
Polysaccharides from Eukaryotes (Vol. 6, pp. 481-574). Weinheim: Wiley-VCH.

11. Alemdaroğlu, C., Değim, Z., Celebi, N., Zor, F., Oztürk, S., \& Erdoğan, D. (2006). An investigation on burn wound healing in rats with chitosan gel formulation containing epidermal growth factor. Burns, 32(3), 319-327. http://dx.doi.org/10.1016/j. burns.2005.10.015. PMid:16527411

12. Muzzarelli, R. A. A. (1997). Human enzymatic activities related to the therapeutic administration of chitin derivatives. Cellular and Molecular Life Sciences: CMLS, 53(2), 131-140. http:// dx.doi.org/10.1007/PL00000584. PMid:9118001

13. Ueno, H., Yamada, H., Tanaka, I., Kaba, N., Matsuura, M., Okumura, M., Kadosawa, T., \& Fujinaga, T. (1999). Accelerating effects of chitosan for healing at early phase of experimental open wound in dogs. Biomaterials, 20(15), 1407-1414. http:// dx.doi.org/10.1016/S0142-9612(99)00046-0. PMid:10454012

14. Ueno, H., Mori, T., \& Fujinaga, T. (2001). Topical formulations and wound healing applications of chitosan. Advanced Drug Delivery Reviews, 52(2), 105-115. http://dx.doi.org/10.1016/ S0169-409X(01)00189-2. PMid:11718934

15. Ueno, H., Nakamura, F., Murakami, M., Okumura, M., Kadosawa, T., \& Fujinaga, T. (2001). Evaluation effects of chitosan for the extracellular matrix production by fibroblasts and the growth factors production by macrophages. Biomaterials, 22(15), 2125-2130. http://dx.doi.org/10.1016/S0142-9612(00)00401-4. PMid:11432592

16. Raymond, L., Morin, F. G., \& Marchessault, R. H. (1993). Degree of deacetylation of chitosan using conductometric titration and solid-state NMR. Carbohydrate Research, 246(1), 331-336. http://dx.doi.org/10.1016/0008-6215(93)84044-7.

17. Damian, C., Beirão, L. H., Francisco, A., Espírito Santo, M. L. P., \& Teixeira, E. (2005). Quitosana: um amino polissacarídio com características funcionais. Alimentos e Nutrição, 16(2), 195-205. Recuperado de http://serv-bib.fcfar.unesp.br/seer/ index.php/alimentos/article/view/320/310

18. Lin, K. W., \& Chao, J. Y. (2001). Quality characteristics of reduced-fat Chinese-style sausage as related to chitosan's molecular weight. Meat Science, 59(4), 343-351. http://dx.doi. org/10.1016/S0309-1740(01)00084-5. PMid:22062958

19. Santos, J. E., Soares, J. P., Dockal, E. R., Campana, S. P., Fo., \& Cavalheiro, E. T. G. (2003). Caracterização de quitosanas comerciais de diferentes origens. Polímeros, 13(4), 242-249. http://dx.doi.org/10.1590/S0104-14282003000400009.

20. Veiga, S. C. P. (2011). Estudos físico-químicos de N-acetilação de quitosanas em meio homogêneo (Dissertação de mestrado). Universidade de São Paulo, São Carlos.

21. Oliveira, A. M., Franco, T. T., \& Oliveira, E. M. Jr (2014). Physicochemical characterization of thermally treated chitosans and chitosans obtained by alkaline deacetylation. International Journal of Polymer Science, 2014(2014), 1-9. http://dx.doi. org/10.1155/2014/853572.

22. Rinaudo, M., Desbrières, J., Le Dung, P., Thuy Binh, P., \& Dong, N. T. (2001). NMR investigation of chitosan derivatives formed by the reaction of chitosan with levulinic acid. Carbohydrate Polymers, 46(4), 339-348. http://dx.doi.org/10.1016/S01448617(00)00333-7.

23. Brugnerotto, J., Lizardi, J., Goycoolea, F. M., ArgüellesMonal, W., Desbrières, J., \& Rinaudo, M. (2001). An infrared investigation in relation with chitin and chitosan characterization. Polymer, 42(8), 3569-3580. http://dx.doi.org/10.1016/S00323861(00)00713-8.

24. Chaves, J. A. P., Bezerra, C. W. B., Silva, H. A. S., \& Santana, S. A. A. (2009). Caracterização e aplicação do biopolímero quitosana como removedor de corante têxtil presente em meio aquoso. Cadernos de Pesquisa, 16(2), 36-43. Recuperado de 
http://www.pppg.ufma.br/cadernosdepesquisa/uploads/files/ rev2009_2_05_36-43.pdf

25. Brito, D., \& Campana-Filho, S. P. (2007). Kinetics of the thermal degradation of chitosan. Thermochim. Thermochimica Acta, 465(1-2), 73-82. http://dx.doi.org/10.1016/j.tca.2007.09.008.

26. Madden, J., \& Arem, A. (1991). A cicatrização das feridas: aspectos biológicos e clínicos. In D. Sabiston (Ed.), Tratado de cirurgia (pp. 156-168). Rio de Janeiro: Guanabara Koogan.

27. Oliveira, S. T., Leme, M. C., Pippi, N. L., Raiser, A. G., \& Manfron, M. P. (2000/2001). Formulações de confrei (Symphytum officinale L.) na cicatrização de feridas cutâneas de ratos. Revista da FZVA, 7/8(1), 65-74. Recuperado de http://revistaseletronicas.pucrs.br/ojs/index.php/fzva/article/ view/2126/1635

28. Okamoto, Y., Kawakami, K., Miyatake, K., Morimoto, M., Shigemasa, Y., \& Minami, S. (2002). Analgesic effects of chitin and chitosan. Carbohydrate Polymers, 49(3), 249-252. http://dx.doi.org/10.1016/S0144-8617(01)00316-2.

29. Lee, Y. M., Kim, S. S., Park, M. H., Song, K. W., Sung, Y. K., \& Kang, I. K. J. (2000). $\beta$-Chitin-based wound dressing containing silver sulfurdiazine. Journal of Materials Science. Materials in Medicine, 11(12), 817-823. http://dx.doi. org/10.1023/A:1008961730929. PMid:15348066

30. Ravi Kumar, M. N. V. (2000). A review of chitin and chitosan applications. Reactive \& Functional Polymers, 46(1), 1-27. http://dx.doi.org/10.1016/S1381-5148(00)00038-9.

31. Laranjeira, M. C. M., \& Fávere, V. T. (2009). Quitosana: biopolímero funcional com potencial industrial biomédico. Quimica Nova, 32(3), 672-678. http://dx.doi.org/10.1590/ S0100-40422009000300011.

32. Tomida, H., Fujii, T., Furutani, N., Michihara, A., Yasufuku, T., Akasaki, K., Maruyama, T., Otagiri, M., Gebicki, J. M., \& Anraku, M. (2009). Antioxidant properties of some different molecular weight chitosans. Carbohydrate Research, 344(13), 1690-1696. http://dx.doi.org/10.1016/j.carres.2009.05.006. PMid:19559405

Enviado: Maio 23, 2014

Revisado: Ago. 20, 2014

Aceito: Nov. 14, 2014 